\title{
The Professional Challenges Facing General Psychologists
}

\author{
Eric P. Charles
}

Journal für Psychologie, 26(1), 123-130

https://doi.org/10.30820/8247.08

www.journal-fuer-psychologie.de

\section{Zusammenfassung}

Die Professionellen Herausforderungen für Allgemeine Psychologinnen und Psychologen

An einer Allgemeinen Psychologie zu arbeiten, führt zu typischen und erwartbaren intellektuellen Herausforderungen, da führt kein Weg dran vorbei. Ebenso führt sie jedoch auch zu professionellen Herausforderungen, mit denen sich die, die eine engere Spezialisierung wählen, nicht befasst sind. Diese zusätzliche Hürde können wir reduzieren. Es braucht eine Anstrengung um Generalisten die gleichen institutionellen Rahmenbedingungen zur Verfügung zu stellen, wie Generalisten. Die professionellen Schwierigkeiten, auf die Generalisten stoßen, die eine Allgemeine Psychologie konzipieren wollen, sind ein genauso großes Hindernis, wie die Schwierigkeiten, verständliche Theorie zu entwerfen.

Schlüsselwörter: Allgemeine Psychologie, professionelle Wissenschaftler, Wissenschaft, Bildung

\section{Abstract}

Working towards a general psychology presents the usual challenges one would expect from an intellectual pursuit, and there is no way around that. However, it also presents a host of professional challenges not faced by those who choose a more narrow specialization, and there is the possibility of reducing that additional hurdle. An effort needs to be made to provide generalists with something akin to the institutional infrastructure that facilitates the careers of specialists. The professional difficulties faced by people pursuing careers as generalists is as big of an obstacle to our achieving a general psychology as are any of the difficulties in creating comprehensive theory.

Keywords: general psychology, professional research, academia, education 


\section{The Professional Challenges Facing General Psychologists}

A decade ago, I contributed to an issue of this journal focused on changing paradigms in psychology curricula, and the pressure many European Psychologists feel to adopt the U.S. model (Charles, 2008). In that article I outlined several weaknesses in Introductory Psychology courses, as commonly taught in the U.S., and described the negative effects of such classes on students, faculty, and the field at large. Among other problems, the structure of that course discourages the idea that there can be a »general psychology.« To the extent that such a course might inspire students to think about approaches to psychology, the options students are presented with are dictated by arguments over 100 years old, and the students are encouraged to see the points of view represented in those arguments as irreconcilable.

Students are taught that there are Freudian approaches, behaviorist approaches, humanistic approaches, and others. After being told this, the approaches appear now and then in chapters such as $\gg$ Development « and $\gg$ Personality «, but remain oddly absent from other chapters, such as »Perception « - though perhaps the Gestalt approach shows up a bit there. Though narration regarding such squabbles once pervaded the remainder of undergraduate and graduate education in the U.S., such narrations are now largely absent from intermediate and advanced classes. Instead of emphasizing squabbles, those course guide students towards simply thinking about the field in a modular way. That is, rather than encouraging students to see connections across psychology's sub-disciplines, each course is simply taught as a disconnected unit, with students discouraged from trying to reconcile things they are taught in different classes. The undergraduatetrained tendency to view the field in a disjointed way is developed further in graduate school, and eventually reproduces itself as a disjointed field, in which it is very difficult to have a career as a general psychologist. The few who make it through the process inclined to do general work are viewed as oddities, and their value is unclear to people who are unconcerned with trying to achieve a broader understanding of what it means to be » a psychologist. « Most members of the field simply have very little vision regarding how their specialty connects to other specialties, and this limits the support they can and do provide to people who are trying to contribute to the field more broadly.

The need for faculty to so strongly narrow their professional identity circles back to influence their students, via course work and mentorship, and thereby reinforces those fractures in future generations. As generations accumulate under such a system, specialization brings an ever growing number of practical professional advantages. A hyperspecialist who is lucky enough, or prescient enough, to end up in a hyper-specialty with a functional community is better off still. The primary challenges created for the generalist eventually shifts from the intellectual difficulty of working across specialties, to the difficulties of making a career without the support available to your colleagues. To 
be as explicit as possible, it is my belief that: Professional challenges create more onerous burdles for moving towards a general psychology than does a lack of decent theory.

If people cannot build a career around a broad identity as $\gg$ a psychologist «, being forced instead - by practical concerns - to self-identify only with their very narrow research specialty, then it is no wonder that progress in general psychology remains elusive. Combined with the hegemonic power of the specialists, exerted as new psychologists emerge from graduate programs and advance in their careers, it is no wonder that we are still wondering what a general psychology would look like. The solicitation which inspired this article asked: »Can we pluralize research and shift from mostly separated and disconnected areas of lower functions towards a renewed holistic image of the psychological person? « My answer is that we can, if we recognize that the crucial factors holding us back are largely socio-cultural issues regarding how we enact »psychological science.«

\section{Anecdotal Evidence - The Society for General Psychology}

I will not draw upon traditional (large-N) empirical evidence to support these claims. Instead, I will draw upon the experience of several peers, as well as my personal experience, which includes time spent as an academic psychologist and as an applied research psychologist. In my academic life, I have also done much work on potentially unifying theories of psychology, i. e. theories capable of bringing together large swaths of the field, including editing a special issue of The Review of General Psychology (Charles, 2013a). I also spent several years heading the Early Career Psychologists Committee for The Society for General Psychology. That society is also known as »Division 1 « of the American Psychological Association (APA), though the society's members need not be members of the APA. ${ }^{1}$

The Society for General Psychology offers a microcosm for the difficulties facing those interested in becoming general psychologists. Membership peaked in 1988 at over 6,000 members (Dewsbury, 2014). As of 2012 the membership directory had that down to only 1,390 members. The drop in membership is not, however, as concerning as how top-heavy the remaining membership is. The roles included $473>$ fellows $<$ of Division 1, $806>$ members $<$, and $111>$ associates $<$. Fellows are senior members of the field, recognized for their contribution to general psychology, who can presumably influence many others via direct mentorship and indirect professional support. And yet, if, over the past 20 years, each fellow had attracted only 2 other people to the division (students, colleagues, or anyone else who their works and deeds inspired), that would account for all division membership. Clearly, then, even for those recognized for their significant contributions to general psychology, encouraging others to engage in the effort is not a top priority. Phrased proactively, if every fellow put it upon themselves to get 
two new members involved, the society would double in size almost instantly. Though there are notable and praiseworthy exceptions, it is ever more the case that identifying as a $\gg$ General Psychologist « is as a privileged pastime of the senior statesman.

\section{The Benefits of Narrow Specialization}

The benefits of specialization are many, but key here are the institutionized benefits for those starting a career. I have been on the periphery of thriving specializations, and deeply involved in several marginalized specializations. Even the marginalized ones provide a firm infrastructure that can help support a career: The specialty has key journals and conferences. The major players are fairly obvious. There is general agreement about what »good work « looks like when it comes out in print or is presented at a conference. A decent consensus regarding what good work entails creates, among other things, a built-in intuition about how new projects relate to other efforts in the field and, by virtue of that, a built-in intuition about how emerging scholars relate to established scholars. Funding sources, if not generous, are understood, and the means for seeking funding is clear. This leads to conversations such as: $\gg$ Did you see project $\mathrm{X}$ ? That must be the new student from Lab Y.« »Yes, she should post-doc with Z, I'll bet she can get on the same grant as ... « etc.

As the student emerges in the profession, the institutional benefits of specialization continue. They receive notices of special issues in journals, of upcoming conferences relevant to their work, and join list serves where their work is clearly relevant. They know people who are on the editorial boards of their specialized journals, people who serve on the committees that control grants, and those in professional organizations in which service will »get your name out there « in the right ways. Being part of an established field allows people to pretty easily figure out who they would recommend to review a paper, and who they would like to see serving on a tenure-review committee. And, as you go through your career, it is possible to gauge how you are doing relative to your peers; when someone gets tenure, or receives an award, you can tell if they are in your specialty or not, and see how your work stacks up to theirs. While some of those benefits are more profoundly available to skilled social actors, others of them are institutionally present regardless of the ability to work a room or nurture long-term collaborations.

Note that, the narrower the specialty, the more such benefits are facilitated without any special effort on the part of those involved, so long as the specialty maintains a critical mass of researchers. Being active within such a specialty will simply produce the listed benefits. In contrast, spending significant time doing general work that connects typically-disparate research areas, in ways not of immediately obvious value to the specialists, will muddle those processes. 


\section{The General Psychologist's Professional Dilemma}

The situation for the generalist is typically the opposite of what is described above. The simple process of being an active member of the wider field of psychology, contributing cross-specialty and multi-specialty work, does not automatically produce those benefits. The efforts of a generalist do not feed into a similar institutional context, and the instructional structures designed to support specialists will not pick up the slack.

If you do work that merges insights from developmental psychobiology with those from social cognition research, which conference will give that a good billing? Who should review the paper, and for what journal? Does the national agency have a funding mechanism to facilitate the continuation of the research? How do you relate to other generalists, such as someone writing about the relationship between behaviorist and Freudian theory in the context of their applied work in organizational psychology? Or someone who has spent 30 years on the history and theory of psychology writ large? Let us grant that you are best general psychologist of your generation. Who will attest to that in a glowing letter of recommendation? Who will attest to it when you go up for tenure or professional accreditation? In short: How will you have a career?

This is not to say that such careers are impossible. It is simply to point out that they lack the naturalness of the specialized careers enjoyed by people who do not give general psychology a thought, or who at least put off such thoughts until very late in the game. Those who pursue a generalist path will have a harder time achieving basic professional milestones.

The only possible counter to these obstacles is an outlay of effort to create such institutional infrastructures, with the understanding that they will take more effort to maintain than would be the case for a narrow specialization. And because institutional support is the solution, buy in is needed from established and recognized members of the profession. It is the same formula as the efforts to increase professional representation among women and ethnic minorities in the profession. While sometimes phrased as attempts to give the disadvantaged group a leg up, such efforts are also often phrased as simply providing those people with the advantages that seems to come more-or-less automatically to their white, male, non-disabled counterparts.

We need list serves and newsletters and journals. While some of those exist, they need to be pushed further to fill in the support-gaps experienced during a generalist's career. If »General Psychology« is to be a thing, then there must be people willing to provide mentorship to other general psychologists, there must be the celebration of successes by general psychologists, there must be informal networking between generalists. Because it is not obvious otherwise, special efforts need to be made to announce those willing to review papers, serve on tenure committees, etc. Special effort needs to be made by senior members of the field to create serious publishing opportunities and 
funding situations. This includes serving within the organizations that control funding, arguing for generalist proposals when they come forward, and helping mentor members of the field in how to be more competitive for said funding.

In short, »general psychologist « needs to be treated as if it were a type of specialization. This is no small ask. People raised in a context that nurtures specialization need to begin to see other generalist as a member of the same community, even if the questions asked by the generalists have no overlap beyond being »general.«

\section{How General are We Talking?}

In these efforts, one crucial question will eventually be » what is meant by general psychology «? While I leave it to others to discuss that now, I do have one important thing to add: I have elsewhere argued that Psychology is the scientific study of phenomenology and epistemology (Charles, 2013b). The two basic questions of psychology are »What is the nature of knowledge? « and »What is the nature of experience? « But psychology also includes the full range of measurement questions and applied questions that grow from that starting point, including questions about abnormal and clinical psychology, as well questions about applied work in education and human factors. I offered illustrations of this breadth as shown in figure 1 and 2 .

My goal here is not to argue for the view illustrated in figure 1 and 2; those interested are referred to the cited paper. Rather, my goal is to use those illustrations to emphasize the range of activities that we must be open to supporting, if our goal is to support generalists. We need to maintain a broad enough vision that we do not begin to alienate people whose work can reasonably be considered part of the field.

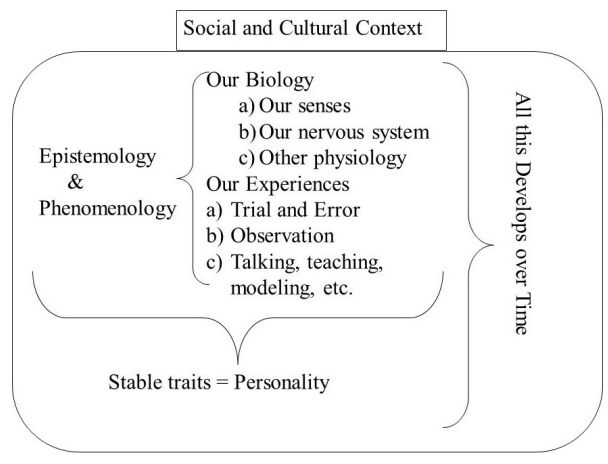

Fig. 1 


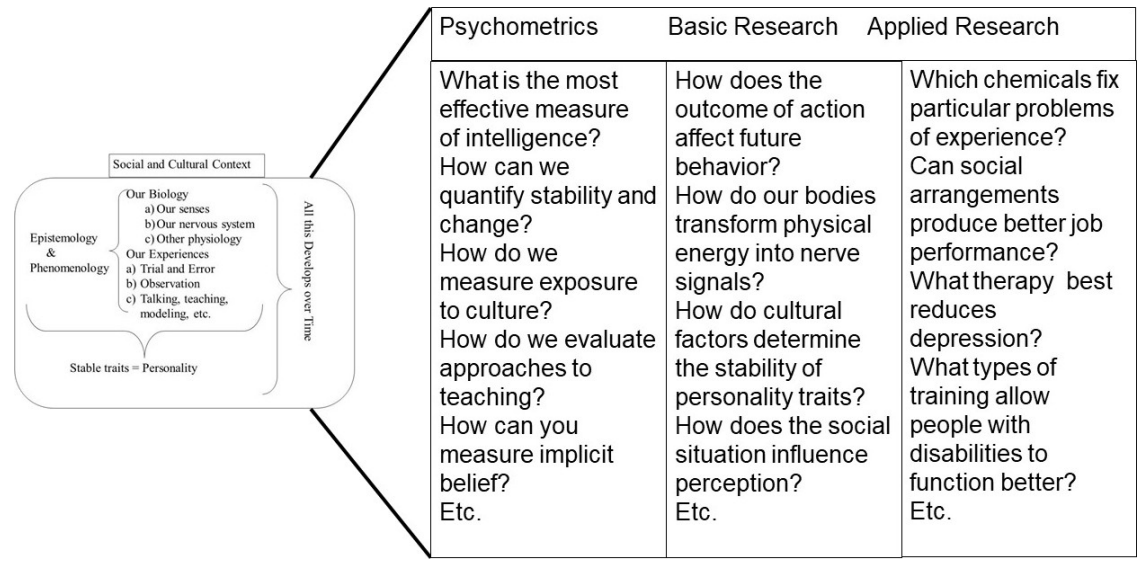

Fig. 2

\section{Conclusion}

As the practitioners become ever more specialized, the profession of psychology becomes ever more fractured. The challenge of creating good theory, theory that can mend those fractures, is great. The challenge is compounded by the professional struggles one is likely to face while trying to build such theories, struggles less likely to be faced by specialists, due to the institutional support that naturally comes with specialization. If we want to have a general psychology in the future, we need to make a concerted effort to ensure that those pursuing general issues are able to have successful careers. This requires the creation of institutional support structures that can provide generalists with resources akin to those provided to specialists.

\section{Note}

1 Much of what is presented here was previously presented in the Society's newsletter, or in private reports made to the leadership committee of the society in my role on the Early Career Committee. 


\section{References}

Charles, E. (2008). Eight Things Wrong with Introductory Psychology Courses in America: A Warning to My European Colleagues. Journal für Psychologie, 16(1). https://www.journal-fuer-psychologie. de/index.php/jfp/article/view/196/133

Charles, E.P. (2013a). Unifying Approaches to Psychology. Review of General Psychology, 17(2).

Charles, E.P. (2013b). Psychology: The empirical study of epistemology and phenomenology. Review of General Psychology, 17(2), 140-144.

Dewsbury, D. A. (2014). The origins of Div. 1 and its presidents. The General Psychologist, 49.

\section{About the Author}

Eric P. Charles, Manpower Studies and Analysis Branch, Manpower and Reserve Affairs Department, Headquarters Marine Corps, United States Marine Corps, Quantico, Virginia \& Department of Public Administration and Policy, School of Public Administration, American University, Washington, DC.

Contact: echarles@american.edu

This publication does not represent the opinion of the Marine Corps. 